\title{
Effect of aerosol challenge with sensitising antigen on the permeability of the surface of the rat trachea in life
}

\author{
SASHWATI MUKHERJEE, PETER HEAP, FLEMING CARSWELL \\ From the Respiratory Research Group, Department of Child Health and Department of Anatomy, University of \\ Bristol
}

ABSTRACT A rat model of immediate pulmonary hypersensitivity was used to investigate the permeability changes in the tracheal epithelium produced by aerosol challenge with antigen. The rats were sensitised by the intraperitoneal injection of antigen (dinitrophenyl (DNP ${ }_{19}$ ) ovalbumin). Sensitised and control animals were then challenged for 60 minutes with an aerosol of the same antigen, which also contained the electron dense pore marker lanthanum. Histological examination and $x$ ray probe microanalysis showed a greater intercellular concentration of lanthanum in the tracheal epithelium in sensitised than in control animals. The results show that in sensitised rats increased intercellular penetrance of antigen can occur after antigen challenge.

\section{Introduction}

Antigen challenge of sensitised monkeys leads to increased concentrations of inhaled radiolabelled albumin in the blood, suggesting that sensitisation is associated with increased airways permeability to antigen. ${ }^{1}$ Allergen challenge has also been shown to increase the blood concentration and bronchoconstrictor effect of aerosolised radiolabelled histamine. ${ }^{2}$

The sensitised rat is a useful model for investigation of the histological effects of immediate pulmonary hypersensitivity. ${ }^{34} \mathrm{We}$ previously investigated the route of penetration of inhaled antigen into the pulmonary tissue by using a radioactive aerosol of antigen (dinitrophenyl ovalbumin-DNP ${ }_{19}$ ovalbumin). After challenge with tritiated $\mathrm{DNP}_{19}$ ovalbumin sensitised rats had more radioactive antigen in pulmonary tissue than unsensitised rats and the spaces between ciliated tracheal cells were wider. The use of a pore marker, lanthanum, ${ }^{6}$ confirmed increased penetration along the intercellular boundaries when the aerosol was combined with a fixative. ${ }^{7}$ The possibility that lanthanum had penetrated from the submucosa was not excluded in that

\footnotetext{
Address for reprint requests: Dr F Carswell, Director, Respiratory Research Group, Department of Child Health, Royal Hospital for Sick Children, Bristol BS2 8BJ.
}

Accepted 26. September 1988 experiment. It is also possible that mucosal permeability may not be increased in life and that fixation itself produces the apparent increase in permeability. We have therefore examined whether aerosol challenge of sensitised animals with antigen causes an increase in permeability of the respiratory epithelium lining in life.

\section{Methods}

\section{PROCEDURES}

Inbred Chester Beatty rats maintained in the University of Bristol Medical School animal house were used. Males weighing about $200 \mathrm{~g}$ were injected intraperitoneally with saline (group A) or $10 \mu \mathrm{g} \mathrm{DNP}_{19}$ ovalbumin (group B) 21 days before challenge. A booster intraperitoneal injection of $1 \mu \mathrm{g}$ of the same antigen was given three days before challenge.

\section{AEROSOL CHALLENGE}

All animals were anaesthetised with $10 \mathrm{mg} / \mathrm{kg}$ intraperitoneal sodium pentabarbitol (Sagatal) and while breathing spontaneously were placed in a constant volume body plethysmograph. ${ }^{38}$ All were exposed for one hour to $20 \mathrm{mg} / \mathrm{ml} \mathrm{DNP}_{19}$ ovalbumin containing $3 \%$ lanthanum nitrate, presented as an aerosol produced from a Bennett twin nebuliser. The nebulisate was changed every 15 minutes to maintain its (measured) osmolality around $280 \mathrm{mosmol} / \mathrm{kg}$, which is isosmotic with rat plasma. 


\section{RESPIRATORY RESPONSE}

Respiratory reactivity to aerosol challenge was measured as the percentage of expirations showing "expiratory notching," measured over more than 20 breaths, ${ }^{34}$ expiratory notching being defined as a brief interruption of expiratory flow. We have previously shown it to be a good index of the pulmonary hypersensitivity reaction in the rat. ${ }^{8}$ The person assessing pulmonary reactivity and lanthanum penetration (SM) was unaware of which animals were sensitised.

\section{TISSUE PREPARATION AND ELECTRON MICROSCOPY}

Rats were killed immediately after challenge. Tracheal tissue was excised and fixed by immersion in 3\% glutaraldehyde in phosphate buffered saline (pH 7.3) at $4^{\circ} \mathrm{C}$ for five hours. It was rinsed overnight in phosphate buffered saline at $4^{\circ} \mathrm{C}$ and then postfixed in $1 \%$ osmium tetroxide in phosphate buffered saline at room temperature for two hours. The tissues were dehydrated in graded ethanol solutions and embedded in epoxy resin (Araldite). Pale gold sections (about $600 \AA$ thick) were cut and mounted on copper grids. The grids were placed in a Hexaland graphite spectrometer holder with a Faraday cage and viewed unstained in a JEOL 200 CX TEM/SCAN analytical electron microscope fitted with a $\mathrm{KeVeX} 500 \mathrm{~A} / 6000$ $x$ ray energy spectrometer. Transmission electron micrographs of sections were prepared.

The lanthanum content of $260 \mu \mathrm{m}^{2}$ areas of epithelium at sites below the level of the tight junctions was measured by means of $x$ probe microanalysis in the scanning transmission mode. $X$ ray analysis was standardised for a live time of 100 seconds and counts are expressed as mean counts/100 seconds. ${ }^{7}$ Ten sections were analysed for each animal and the results expressed as the ratio $(P-B) / \mathrm{W}(P$ denotes peak lanthanum counts, $B$ background $x$ ray counts, and $\mathrm{W}$ white radiation). White radiation is a factor used to cancel out any non-specific $x$ rays and variations due to tissue thickness. ${ }^{9}$

\section{ANALYSIS}

The data were analysed by means of Student's $t$ test and results are presented as means and standard errors.

\section{Results}

Lanthanum was detected in the lumen, microvilli, and intercellular spaces in the sensitised animals (group B) after challenge with $\mathrm{DNP}_{19}$ ovalbumin (fig 1). Lanthanum concentration was greatest at the airway surface and decreased progressively towards the connective tissue. In contrast, the unsensitised rats show negligible lanthanum in the lumen or within the tissue (fig 2): only careful search shows some luminal lanthanum in control tissues (fig 2 , insert). $X$ ray probe micro- $\stackrel{P}{\stackrel{P}{9}}$ analysis showed more lanthanum in the epithelium of group B than group A rats (mean 43 (SEM 6.5) $v 12$ 음 $(1.6) ; p<0.01)$.

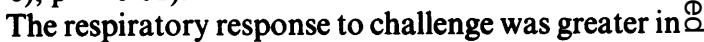
the sensitised rats than in the unsensitised rats $(p<\%$ 0.05 ). The severity of respiratory response and quan- $\vec{\circ}$ tity of lanthanum below the epithelial surface in the DNP $_{19}$ ovalbumin sensitised rats were not, however, $\vec{\omega}$ significantly correlated (Spearman coefficient $=0.73 ;$ $0.05<\mathrm{p}<0.1)$.

\section{Discussion}

The combination of an aerosol of allergen witho electron dense lanthanum has permitted lanthanum to be used as a marker in electron microscope studies of tracheal permeability. ${ }^{6}$ Lanthanum was found to have penetrated the intercellular boundaries of the res-

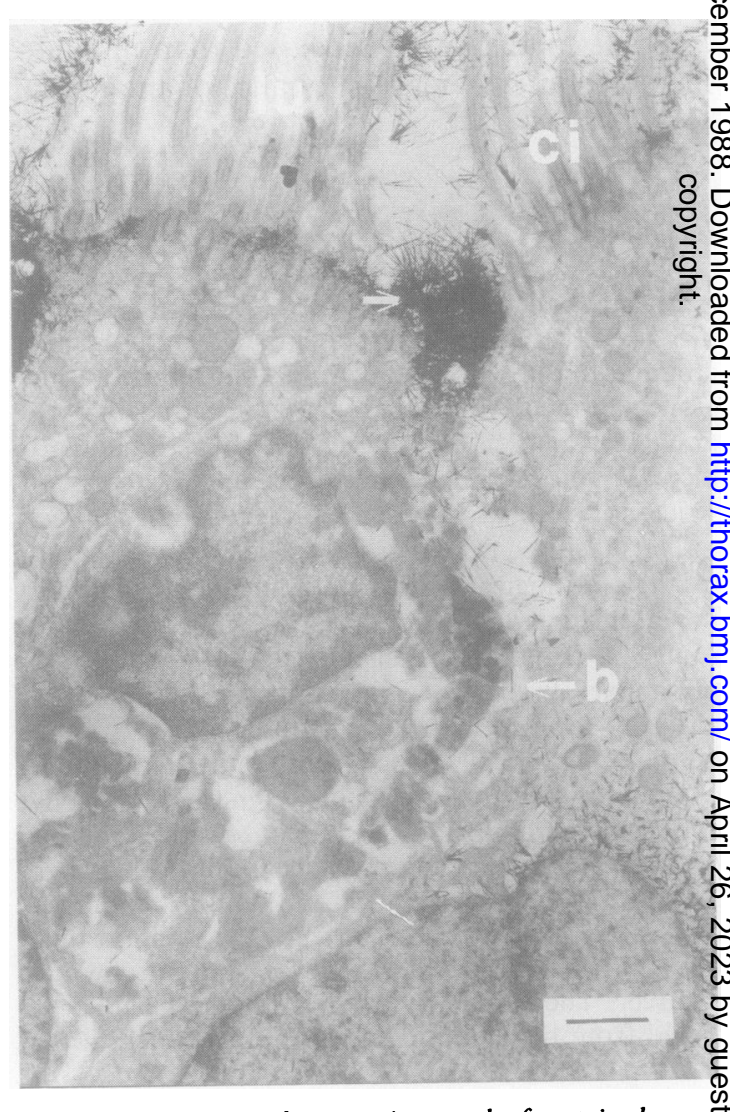

Fig 1 Transmission electron micrograph of unstained tracheal epithelium from a rat sensitised and challenged with $D N P_{19}$ ovalbumin (group B). Lanthanum (O) is visible in the lumen $(\mathrm{Lu})$, cilia $(\mathrm{Ci})$, and intercellular boundaries or spaces (b). (Bar represents $1 \mu \mathrm{m}$.) 


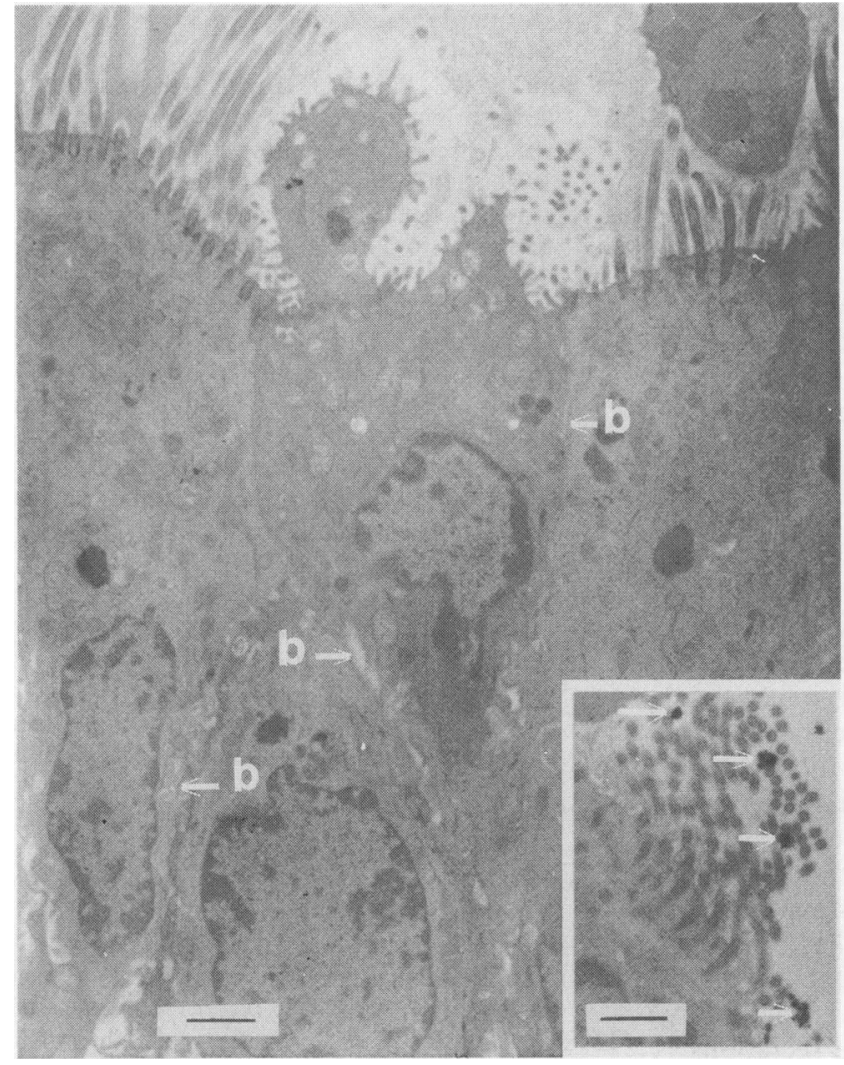

Fig 2 Transmission electron micrograph of unstained trachea from saline treated control rat challenged with dinitrophenyl ovalbumin (group A). No lanthanum is visible in intercellular boundaries or spaces (b). Inset: Example of small quantities of lanthanum (-) found on the luminal surface of trachea from a control animal. (Both bars represent $1 \mu \mathrm{m}$ ) piratory epithelium in sensitised rats whereas there was very little penetration in unsensitised rats. The results suggest that there was increased permeability from the luminal surface of the trachea in life.

There was an apparent increase in lanthanum in the tracheal lumen and epithelial surfaces of sensitised animals. This might imply that the increase in intraepithelial lanthanum may be secondary to increased surface lanthanum. As the experimenter (SM) did not know whether an individual rat was sensitised, this cannot be due to experimenter bias. Equal quantities of lanthanum should have been deposited in the two groups of rats as there was equal exposure to the aerosol. Bronchial narrowing in the sensitised animals could have caused increased deposition of aerosol in the central airways, but this is unlikely as bronchoconstriction did not occur or was minor in our previous studies. ${ }^{8}$ The increased epithelial content could have arisen from epithelial disruption similar to that known to occur in asthma ${ }^{10}$ and after antigen challenge in animals. " This would expose more membranes that the lanthanum could stain or it might act to reduce the microciliary clearance of lanthanum. The increase in luminal lanthanum might be due to leaching out of intraepithelial lanthanum or allergen in the fixation process or it might indicate a difference in the quantity or character of tracheal secretions. An increase in radiolabelled luminal allergen was noted in previous experiments ${ }^{5}$ when sensitised subjects were challenged.

Our previous study ${ }^{7}$ showed that aerosol challenge in sensitised rats leads to increased postmortem penetration of lanthanum along the intercellular boundaries. In the present experiments the lanthanum was applied only in life and postmortem artefact is less likely to explain our findings. The previous results also make it unlikely that the increased lanthanum deep to the tight junctions was merely a result of increased lanthanum at the luminal surface. The present results confirm that after antigen challenge more radioactive antigen is found in trachea and lung tissues from sensitised than from unsensitised rats.

Our previous work showed that sensitisation of rats produces an IgE mediated airway response that can be detected by volume plethysmography and blocked by pretreatment with cromoglycate. ${ }^{34}$ We have found the measurement of expiratory notching to be a sensitive indicator of bronchoconstriction in the rat. ${ }^{8}$ The sensitised group showed a greater increase in expiratory notching on challenge, though the magnitude of this response did not correlate with lanthanum pene- 
tration, possibly because of the small numbers of rats (six) examined. In a previous study lanthanum penetration in the fixed trachea showed a significant relationship with the mechanical response. ${ }^{7}$ In the latter system lanthanum is included in all fixing solutions, so it may be measured more reproducibly than in the present system, where it may be lost from tissues during processing.

Although our results do not show directly that tight interepithelial junctions are open, this is a reasonable extension from other work, ${ }^{12}$ which showed that lanthanum penetration was closely related to the patency of tight junction regions. Inflammatory events in the airway may reduce the tightness of the intercellular junctions, ${ }^{13}$ thereby facilitating the penetration of inhaled antigens or agonists to the submucosal irritant receptors. A mucosal mechanism that allows increased penetration has been suggested as the cause of increased reactivity after cigarette smoke exposure,$^{14}$ ozone challenge, ${ }^{15}$ and viral infections. ${ }^{16}$ Inflammatory reactions change airway permeability in the guinea pig. ${ }^{17}$ Elwood et $a l^{18}$ failed to show any increase in permeability to diethylene triamine pentaacetate (DTPA) in asthmatic subjects, though they did not challenge their subjects with antigen and so the epithelium could have been in a resting state with intraepithelial junctions closed. DTPA has been said to be unsuitable as a marker of permeability as its clearance after deposition in the airways is affected by both the volume and the nature of the secretions, ${ }^{19}$ both of which are altered in asthma. ${ }^{20}$

The present work supports the hypothesis that antigen challenge increases mucosal permeability. The results suggest that this increase in permeability is due to increased intercellular penetration. The increase in permeability is most likely to be due to opening of the tight junctions, though freeze fracture and membrane potential studies following allergen challenge are required to confirm this. Increased permeability could progressively facilitate the penetration of agonists or allergen or both to the deeper mucosal tissues and accentuate the airway response.

We thank the Wellcome Trust for financial support, Mrs J Oliver and Mr P J Summers for technical assistance, and Miss $\mathrm{H}$ Coatsworth for secretarial assistance.

\section{References}

1 Boucher RC, Paré PD, Gilmore NJ, Moroz LA, Hogg JC. Airway mucosal permeability in the Ascaris suum- sensitized rhesus monkey. J Allergy Clin Immunol 1977 60:134-40.

2 Boucher RC, Paré PD, Hogg JC. Relationship betweerD airway hyper-reactivity and hyper-permeability in듬 Ascaris-sensitive monkeys. J Allergy Clin Immunots 1979;64:197-201.

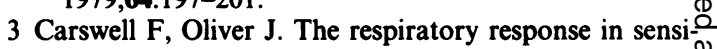
tized rats to aerosol challenge. Immunology 1978;34 is 465-70.

4 Carswell F, Oliver J. The site of respiratory reaction in allergic rats challenged via the airways. Int $\mathrm{Arch} \vec{\omega}$ Allergy Appl Immunol 1978;57:358-63.

5 Morrissey JF, Carswell F. The fate of inhaled antigen within the respiratory tract of sensitized and unsensi tized rats. Monogr Allergy 1983;18:226-30.

6 Shaklai M, Tavassoli M. Lanthanum as an electron $\vec{v}$ microscopic stain. J Histochem Cytochem 1982;30 1325-30.

7 Mukherjee S, Heap P, Carswell F. Lanthanum pene-tration of the trachea after the immediate response of sensitized rats to aerosol antigen. Clin Exp Immunot 1986;65:647-53.

8 Carswell F, Oliver J. Respiratory functional changes on intratracheal challenge of sensitized rats. Respiration 1985;39:138-50.

9 Chandler JA. Recent developments in analytical electron microscopy. J Microsc 1973;98:359-78.

10 Salvato G. Some histological changes in chronic bron $\infty$ chitis and asthma. Thorax 1968;23:168-72.

11 Boucher RE, Hohnson J, Inoue S, Hulbert WC, Hogg $\mathbb{E} C$ The effect of cigarette smoke on the permeabilityo guinea pig airways. Lab Invest 1980;43:94-100.

12 Schneeberger EE. Heterogeneity of tight junction morD phology in extrapulmonary and intrapulmonary air $\mathbb{D}$ ways of the rat. Anat Rec 1980;122:135-8.

13 Hogg JC, Paré PD, Boucher RC. Bronchial mucosa permeability. Fed Proc 1979;38:197-201.

14 Minty BD, Jordan C, Jones JG. Rapid improvement if abnormal pulmonary epithelial permeability after stopping cigarettes. Br Med J 1981;282:1183-6.

15 Murlas CG, Roum JH. Sequence of pathologic changeș in the airway mucosa of guinea pigs during ozonex induced bronchial hyperreactivity. Am Rev Respir Dis 1985;131:314-20.

16 Empey DW, Laitinen LA, Jacobs L, Gold WW, Nadeb JA. Mechanisms of bronchial hyper-reactivity in nor mal subjects after upper respiratory tract infection. AnD Rev Respir Dis 1976;113:131-9.

17 Hulbert WM, McLean T, Hogg JC. The effect of acute inflammation on bronchial reactivity in guinea pigs Am Rev Respir Dis 1985;132:7-11.

18 Elwood RK, Kennedy S, Belzberg A, Hogg JC, Paré PD Respiratory mucosal permeability in asthma. Am Re@ Respir Dis 1983;119:523-7.

19 Barrowcliffe MP. Solute permeability of the alveolag capillary barrier. Thorax 1987;42:1-10.

20 Mezey RH, Cohn MA, Fernandez RJ, Januskiewicz A Wanner A. Mucociliary transport in allergic patient\$? with antigen-induced bronchospasm. Am Rev Respir Dis 1978;118:677-84. 